\title{
A Quantitative Research on The Effectiveness of The Implementation of Supply Chain Management, Logistics \& Marketing Function - The Greek Paradigm
}

\author{
Joel C. Nwaubani, Artemis Tsianta, Magdalini Zelka
}

\begin{abstract}
In today's era of high competition and globalisation, it is an indisputable fact that customers are more demanding not only in the quality of products but also on the services provided. Consequently, the pressure on companies to discover new ways to create and provide quality to their customers has increased much more. More specifically, customer service has become a key tool for diversification, as culture and customer demands are constantly increasing. Greece stands on a strategic crossroad for the development of transportation in the greater region of Europe, Asia and Africa. Its geographical position renders it highly attractive for investments in logistics and transport to take advantage of these increasing trade flows in an efficient and cost-effective manner. In this paper, we carried out a quantitative research in Greece using a questionnaire to analyse the importance and effectiveness of the application of logistics in businesses with regard to customer service, which serve as a critical source of sustainable competitive advantage. By applying this method, a business will have its customers satisfied, thereby giving them the motivation to remain loyal and faithful to their purchasing practices within the company.
\end{abstract}

Index Terms-Supply Chain Management, Logistics Companies, Customer Service, Questionnaire, Greece.

\section{INTRODUCTION}

In Greece, the most worrying, in my humble opinion is the disconnection and detachment of workers from the mentality "of quality" and "quality customer service".

Export of non-quality service is translated to a downward trend for the company. Notwithstanding how a worker must be experienced, he must become not just a participant, but a partner and a companion in this difficult course towards quality. The quality of a customer service is not a matter of achievement by one person, or the respective customer service, but it is a matter of business as a single entity. It is the intention, mood, outcome and the final culmination in teamwork (Anonymous, 2000).

Only very recently, many managers in Greece have come to recognise the importance of "availability", i.e. an efficient logistics system and in conclusion to that of customer service. And of course it is a fact that is not easy to justify as it is widely known that a company should "have the right product, at the right place, and at the right time". Even the more frustrating thing is that, according to relative researches, many business plans, large and well-known companies, seems to take it for granted issues related to distribution and customer service. By improving this

Published on November 29, 2019 "background" is the philosophy of logistics and supply chain management, which have been the focus of developments in recent decades. The idea of integration - consolidation in the company and between companies is not new, but the acceptance of power and reliability is of the manager (Anonymous, 1999).

The good news is that there is a clear evidence of an everincreasing recognition trend from many companies that quality customer service which provides one of the few ways that can differentiate into a world dominated by "clones and cloning", which is a fact that "glove" is conforming or accommodating the business world (Christopher Martin, 2000).

Moreover, it has been observed that given more and more importance to the fact that through logistics and supply chain management the "twins" objectives of reducing costs and improving service provided before customers could be achieved. Better handling of transfer procedures (pipeline) to the customer implies that the customer are been served efficiently and that the cost of providing this service are minimised. The "fusion" of customer service and logistics, which is the main topic of this study should be an integral component of the overall business strategy and not something which stands alone and will be subject to separate management and accountability planning (Terry Harris, 1999).

Indeed, the issue that is presently repeated is that customers have become more than ever demanding and dramatically increasing their expectations towards optimising the service they receive from businesses. Coinciding with this pressure is also the trend of "maturity" of the markets, which leads to a drop of conformity on the brand loyalty, and also the propensity towards the commodity markets). In other words, customers are increasingly less likely to be affected by the traditional approaches to marketing, but instead are more likely to be affected by issues such as availability, speed of response, support from the supplier and all other component of customer service (La Londe J. Bernard, Zinszer H. Paul, 1976).

The conclusion that should emerge from these trends is that the customer service will have to be given a priority in the "agenda of discussions" on the formulation of corporate / business strategy. Bearing this in mind, the idea of this study was arrested under the 3rd Olympus International Conference on Supply Chains (Smith Carol, 2001).

\section{A. Marketing and Sales}

For any company to be successful in the market it is not just important to get new customers, moreover, it has to 
maintain relationships with the existing customers. Logistics strives to provide more and more value-added services that help their customers in meeting the challenges of the modern economy.

Some of the applications of Business Intelligence that can help Logistics achieve this are:

\section{1) Customer Service Portfolio Analysis:}

Marketing managers can do a thorough analysis of the various services offered to different clients on the basis of profitability of these services. Based on this information, they can offer more value-added services to the existing clients.

\section{2) Customer Profitability Analysis:}

Not all customers are equally profitable. Marketing manages can do a detailed analysis of the profitability of all the customers along different factors which affect customerprofitability.

\section{3) Customer Service Level Analysis:}

Marketing managers need to analyse how the company has been performing on various counts with respect to the service level agreement with the customer. Detailed reports and analysis can be made on the reasons and margin by which the service level was not met.

\section{B. Logistics and Marketing Function}

A good company should provide a high level of logistics services to customers. This is a simple idea, but often not directly perceived, especially by some employees e.g. in production planning and control stocks, which apparently have a distance from the market. But the fact is that every employee in the company has a "share" in customer service. Moreover, the levels of domestic and international competition are increasing customer search "tool" to create a sustainable competitive advantage in the marketplace.

For many firms customer service may be the best method of gaining a competitive advantage. The firm may be able to significantly improve its market share and profitability by spending more than competitors on the customer service/logistics. By systematically adjusting the customers' service can improve service package, however, the firm may improve service and reduce the total cost of logistics.

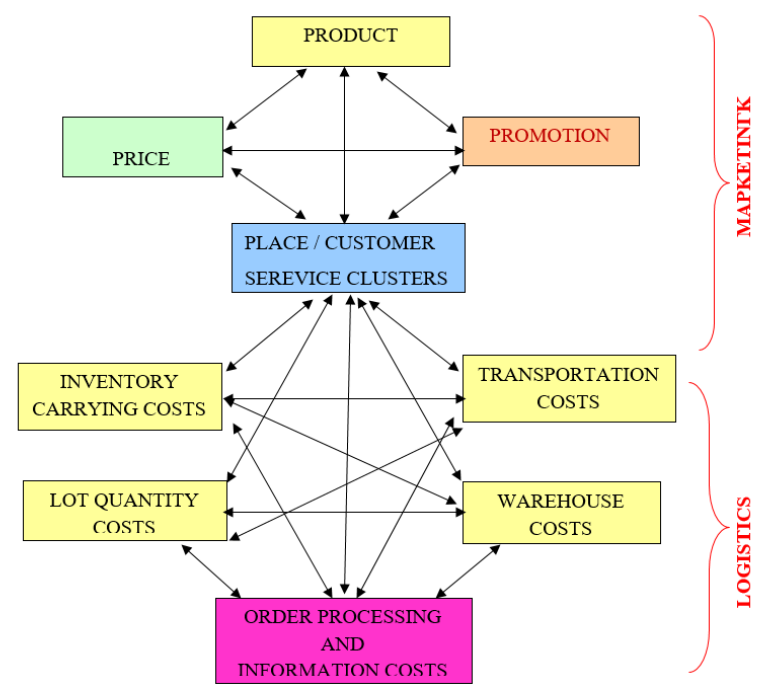

Fig.1. Costs Trade - Offs required in Logistics Source: Strategic Logistics Management, $3 \eta$ Edition (Page 42,264.)

\section{1) Marketing objective:}

Allocate resources to the marketing mix to maximize the long run profitability of the firm.

\section{2) Logistics objective:}

Minimize total costs given the customer service objective where:

Total costs $=$ Transportation costs + Warehouse costs + Order processing and information costs + Lot quantity costs + Inventory carrying costs.

\section{QuANTITATIVE RESEARCH}

We chose quantitative research method because quantitative strategies are seen as more scientific and objective compared to other strategies. Also, the key feature of quantitative research is that it is or aims to be a planned, careful, systematic and reliable way of finding a deep understanding (Loraine Blaxter, Christina Hughes \& Malcolm Tight, 1996).

\section{A. Purpose of using questionnaire}

The purpose of our questionnaire is to find out:

$>$ Which of the selected companies gives priority to a successful differentiation as regards to optimum customer service

$>$ Do these companies evaluate "their customer service" (intermediate or final)

$>$ Do they provide educational training/seminars to employees on "customer service"

$>$ Any availability of a documented policy on "customer service"

The information generated, could be used by the management of these companies to modernize and improve their services, developing modern techniques and generally, to draw conclusions that will help organise better logistics services which will in turn lead to an increase of customers.

\section{B. Definitions:}

Supply chain: according to (Fred Kuglin,1998) setting for the supply chain e.g. a producer is: "The manufacturer and its suppliers, sellers (vendors) and customers, all the connecting links in the company cooperate with the external environment, in order to produce a product or service for which the final customer is willing to pay."

Logistics: One definition of business logistics (Ballou H. Ronald, 1992) speaks of "having the right item in the right quantity at the right time at the right place for the right price in the right condition to the right customer". In other words, Logistics is the management of the flow of things between the point of origin and the point of consumption in order to meet requirements of customers.

Logistics objective: Minimize total costs given the customer service objective where:

Total costs $=$ Transportation costs + Warehouse costs + Order processing and information costs + Lot quantity costs + Inventory carrying costs (Mike Letcher, 2000).

\section{Methodology}

This study is divided into two sections: theory and 
practical. With regard to the theoretical section, there was an extensive literature research that included books and articles in scientific journals in print and electronic form. A key part of this research was conducted at the library of the University of Macedonia in Thessaloniki, as well as on line databases of the library of the same university. Remarkable, however some amount of relevant information was drawn from the city Library of Thessaloniki located at the (National Defense road). Moreover, efforts were made to find data through the daily newspapers, periodicals and special editions of newspapers. Finally, research from the internet on related issues was a great help in the study of customer service.

On the other hand, in our effort to integrate or incorporate our study empirically regarding the approach of this issue, we resorted to developing a questionnaire in order to determine whether and to what extent, these optimal practices are implemented in these companies. The empirical section therefore will be presented, evaluated and generalized information will be collected through questionnaires from selected companies.

\section{POPUlATION}

The population of Greek companies that operates on supply chain management, logistics \& marketing function are as follows:

IKEA HOUSE MARKET S.A. - Furniture, Lighting \& Home Accessories

GERMANOS - General electrical appliances

CHRISTOS KOYNTIS - Electrical appliances

ZELIANIDIS - Meat trading

HELLAS LOGISTICS S.A. - Worldwide network of transport \& Logistics

ATTICA MALL A.E. - Department stores in fashion and cosmetic

HONDOS CENTER A.E. - General stores

AFRODITI A.E. - Supermarket (general trade)

MASOUTIS A.E. - Supermarket (general trade)

AGROMETAFORON - Bauxite trade

ALUMIL A.E. - Construction \& equipment supplies

CHOUTOS CATERING - Catering - Feeds

GALAXIAS A.E. - Supermarket (Cash and Carry Market)

GOODY' S - Fast food

INTRAMET A.E. - Metal \& electromechanical construction

PRAKTIKER - General Trade

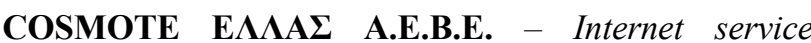
provide

ALFA BETA VASILOPOULOS (AB, AB city, AB Food Market) - Supermarket (General Trade)

FARMA KOUKAKIS S.A. -Dairy products and Drinks, (Farm Industry)

KOTSOVOLOS A.E.B.E. - Computers \& high technology electronic products

PLAISIO COMPUTERS - A.E.B.E. - Computers and office equipment

SKLAVENITIS A.E. - Supermarket, including hypermarkets - (General Trade)

LIDL HELLAS. - Supermarket (General Trade)
FORTHNET S.A. - Internet service provide - Electrical appliances

VODAFON A.E - Internet service provide

BAZAAR SA. - Supermarket (Cash and Carry Market)

OLYMPIAS LOGISTICS S.A. - Logistics / Transport

DIAS S.A. - Specialisation in the field of logistics

DIAKINISIS S.A. - Integrated logistic services and supply chain management solutions

MAKIOS LGISTICS A.E. - Logistics, Transport / Warehousing

\section{A. Samples}

Minimum Base:

Our sample consists of 30 companies chosen randomly. The response rate was about $10 \%$ after about 300 questionnaires were sent.

\section{B. Data processing}

Upon completion, the questionnaires were coded and the responses processed at the statistical software package called, Statistical Package for the Social Sciences (SPSS) and with the help of Microsoft Excel program used for all logical checks of the imputed data and the extraction of the results.

\section{Research findings}

The questionnaire designed consists of Fourteen (14) questions which includes issues related to the purpose of the research. It was conducted in the cities of Thessaloniki, Katerini and Athens from 11- 29 March, 2019. The questionnaire and research findings are presented below.

1) Question 1: Which of the following below do your company gives priority to a successful differentiation as regards to optimal customer service?

- Putting customer first

- Understand customer's definition of service

- Customer care

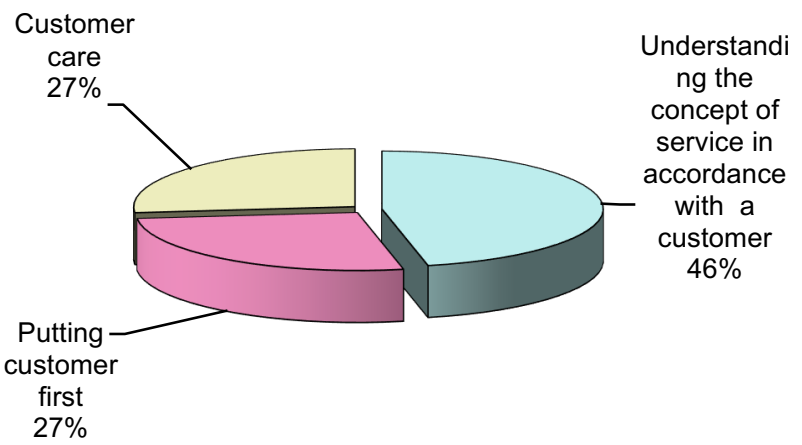

Fig. 2.

From the total respondents (30 companies) it was found that $46 \%$ of the companies said that they put the customer above all, $27 \%$ said they give priority to customer care while $27 \%$ answered that they give priority to the understanding of the concept of service in accordance with a customer.

2) Question 2: It is widely accepted that the customer service concerns the overall company. Could you, however, point out the departments of your company that 
are believed to contribute immensely in the customer service sector?

Accounting-financial department

- Marketing department

- Logistics department

- Human Resources department

- Production department

- Sales department

- Research and Development department (R \&D)

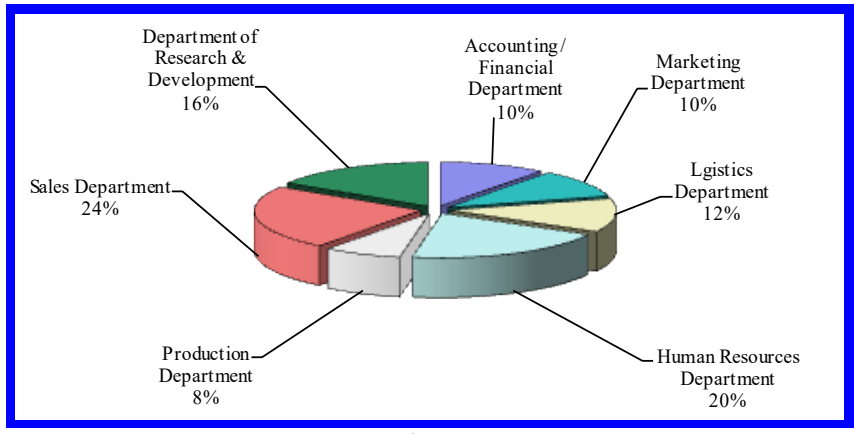

Fig. 3

Out of the total respondents ( 30 companies), it was found that $8 \%$ of Production Department contributes to the customer service, $10 \%$ were attributed to Accounting and Financial Department, the same percentage $(10 \%)$ applies to Marketing Department, $12 \%$ goes to Logistics Department, $16 \%$ to Research and Development (R\&D), Human Resources Department (HR) contributes $20 \%$, while $24 \%$ of the Sales Department contributes in the customer service sector.

3) Question 3 :Do you evaluate the cost of "your customer service" (intermediate or final)?

Total for all customers

For each independently

Establish categories depending on the service cost

We do not evaluate

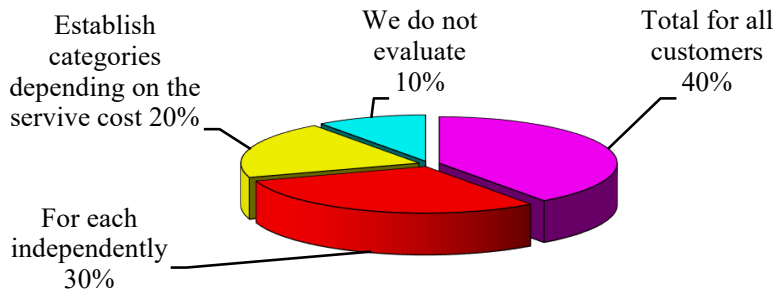

Fig. 4

Figure 4 shows that $40 \%$ of the companies evaluate the total cost of all 'services of their customers', $30 \%$ for each one separately, $20 \%$ establish categories according to service costs, while only $10 \%$ do not evaluate at all.

4) Question 4: Do you provide your company's employees educational training / seminars on "customer service"?

Yes

No

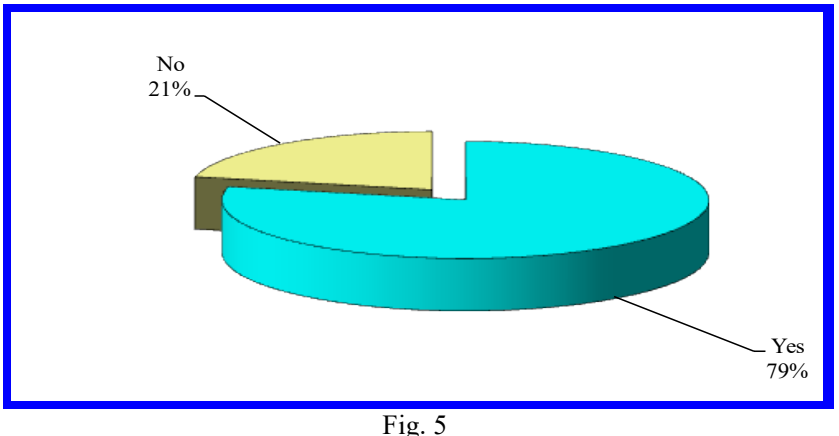

From the above figure, it could be observed that $79 \%$ of the selected companies provide their workers with educational training / seminars on customer service while $21 \%$ do not.

\section{5) Question 5: At what a regular interval does this training takes place?}

Once upon a time

Every six months

Once a year

$>$ Once a year

When necessary

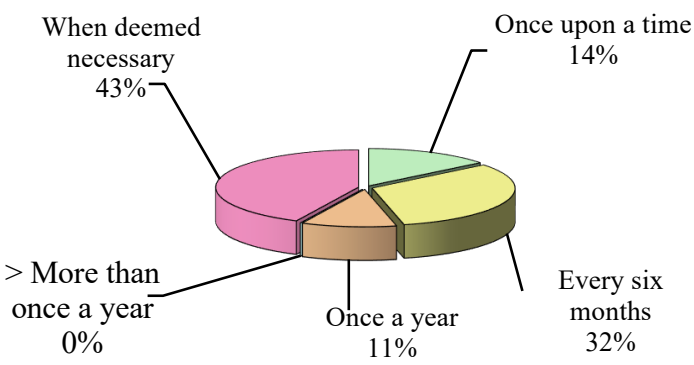

Fig. 6

From the total respondents, the figure above showed that $43 \%$ of these companies provide training/seminars to their employees when deemed necessary, $32 \%$ provide it every six months, $14 \%$ once upon a time, and $11 \%$ provide it annually. Finally, it should be noted that no company was found to be providing training/seminars to their workers more than once a year.

6) Question 6: What/Which departments of your company's employees take part in training courses as regards to customer service?

Accounting-financial department

- Marketing department

- Logistics department

- Human Resources department

- Production department

- Sales department

- Research and Development department (R \&D) 


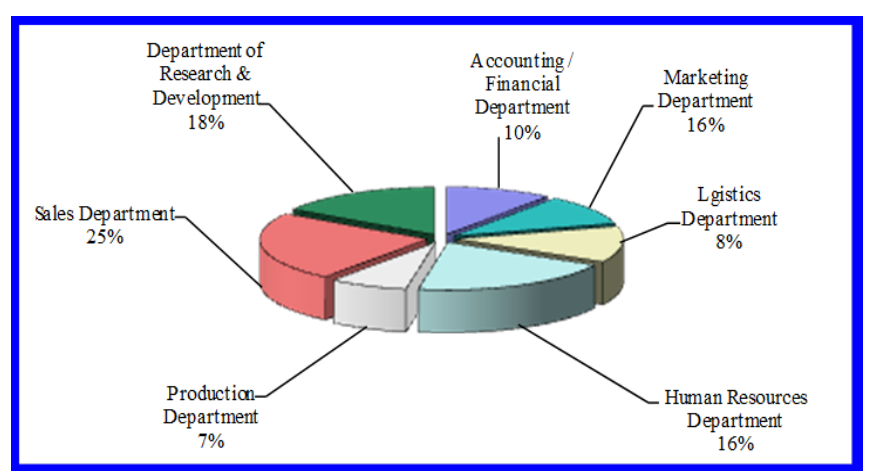

Fig. 7

Figure 7 shows that $25 \%$ of the company workers who takes part in training courses on "Customer service" belongs to the Sales Department, $18 \%$ belongs to the Research and Development Department, 16\% to Marketing Department, The same percentage $(16 \%)$ was recorded to the Human Resources Department, 10\% was observed at the FinancialAccounting Department, 8\% belongs to the Logistics Department, and only $7 \%$ of the Production Department took part in training courses.

7) Question 7: Do you have a documented policy on "Customer Service"?

Yes

No

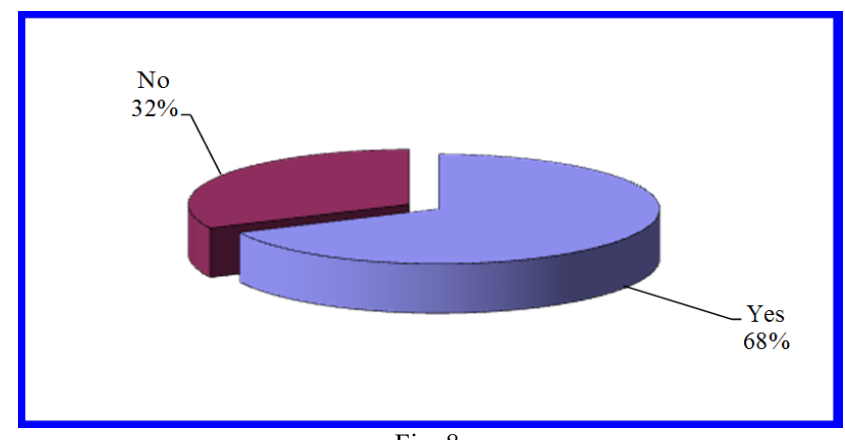

Fig. 8

The figure of this questionnaire shows that $68 \%$ of companies have a documented policy of "customer service", while $32 \%$ do not

8) Question 8: Do your customers receive a copy of this policy?

Yes

No

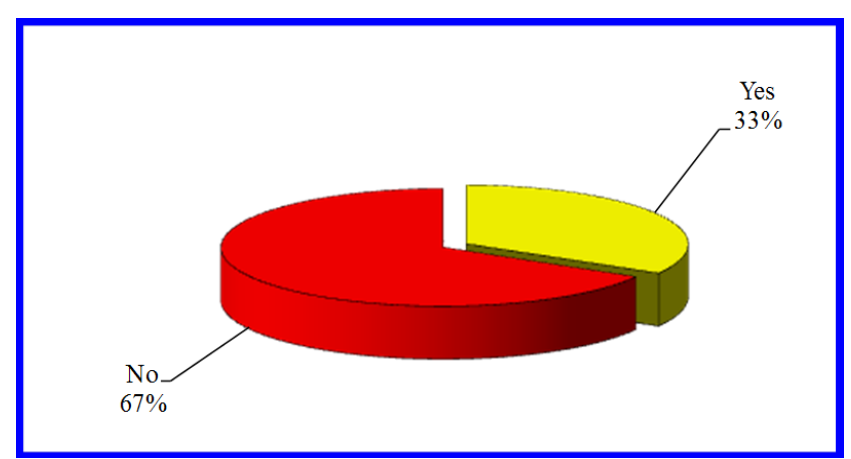

Fig. 9
The figure above from the companies that answered showed that $67 \%$ do not give their costumers a copy of their policy, while $33 \%$ does.

9) Question 9: Have you made any attempt to conducting a research/survey on the meaning of "customer service" for the customers themselves?

- Yes

- No

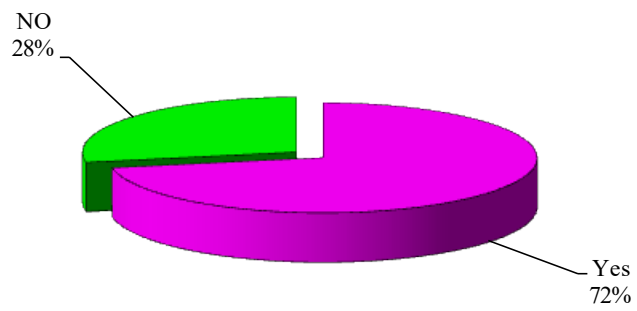

Fig. 10

Figure 10 shows that $72 \%$ of the selected companies have conducted a research on the concept of "customer service" while $28 \%$ do not.

10) Question 10: Please specify below the following ways through which this research took place:

Group interviews

Focus groups

In-depth interviews

Questionnaires

Other

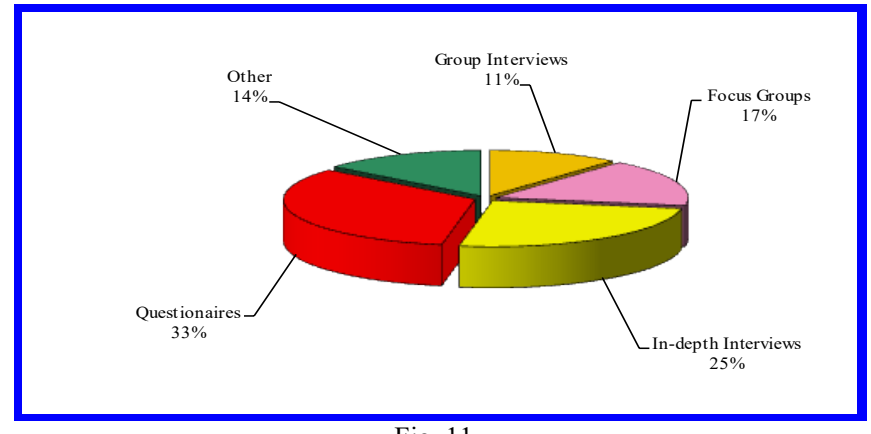

Fig. 11

From figure 11, we could see that $33 \%$ of the selected companies conducted the survey through questionnaires, $25 \%$ through detailed interviews, $17 \%$ through focus groups, $14 \%$ via other method, and the remaining $11 \%$ through group interviews.

11) Question 11: Which of the four dimensions / parameters do you consider to be critical to choosing a supplier by your customers?

Execution time of Order

Quality of sellers' representatives

- Consistency of deliveries

- Support, placement of goods in store

- Completeness of Order

- Regular visits to sellers 
Packaging Quality

- Ease / convenience in the placement of Order

- Responding to queries, questions, complaints

- Installation, guarantees

- Monitoring of stocks of retailers from suppliers

- Technical Support

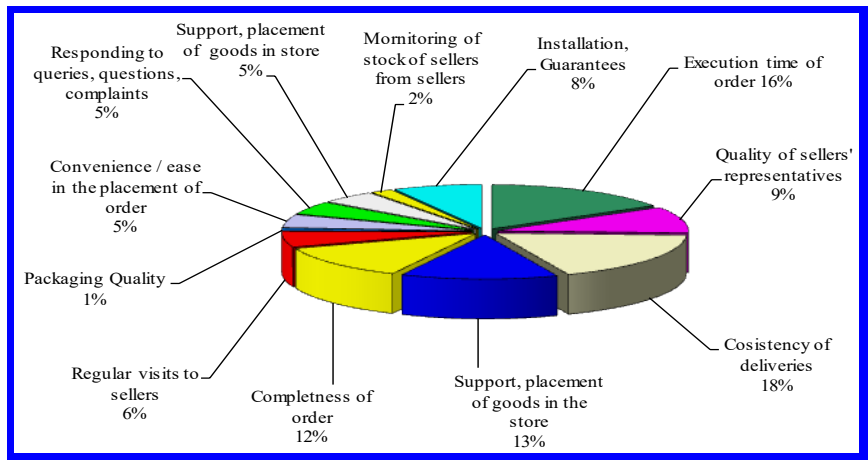

Figure 12

Figure 12 shows that $18 \%$ believe that consistency of deliveries are therefore critical to choose a supplier by your customers, $16 \%$ chose order execution time, $13 \%$ technical support, $12 \%$ completeness of the order, $6 \%$ preferred regular visits to sellers, $5 \%$ to ease/convenience in the placement of order, $5 \%$ support \& placement of goods in the store, $5 \%$ responded to queries, questions \& complaints, $2 \%$ monitoring of inventories by retailers from suppliers, while only $1 \%$ in the packaging quality.

12) Question 12: The basis to enable a company to compete worthily in the present age is to possess a sustainable competitive advantage. Which of the following do you give greater emphasis on the acquisition of competitive advantage?

Product excellence

Process excellence

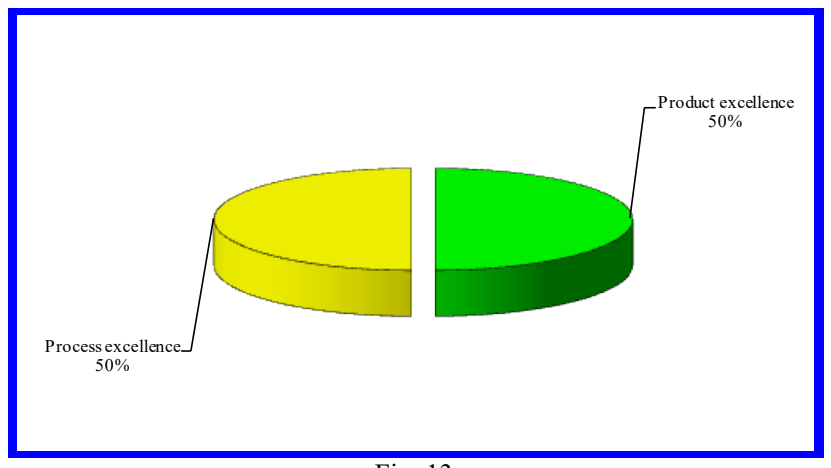

Fig. 13

From figure 13 above, we observed that $50 \%$ of the selected companies are seeking for product optimisation while the remaining $50 \%$ preferred processes optimisation.

13) Question 13: Does your company features a customer service department?

Yes

No

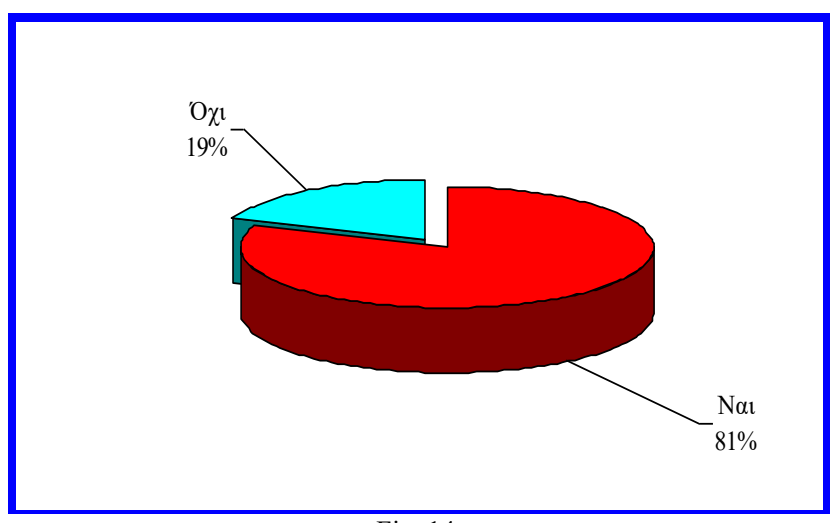

Fig. 14

From the above figure, we could observe that $81 \%$ of the selected companies in Greece have a separate customer service while $19 \%$ do not.

14) Question 14: If yes, where does it belong?

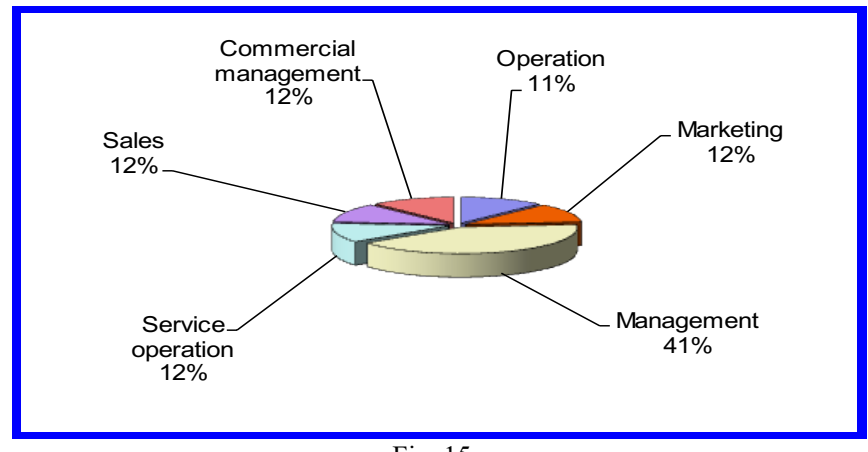

Fig. 15

The figure above emerged that $41 \%$ of the business customer service belongs to the Management, $12 \%$ belongs to Marketing Department, $12 \%$ also was controlled by the Commercial Management, $12 \%$ of the business customer service belongs to the Sales Department, $11 \%$ to the Operation Department, while the remaining $12 \%$ of the business customer service was controlled by the Service Operation.

\section{CONCLUSIONS}

An attempt was made to investigate the current situation in Greece companies that apply or provide customer service. The significance of our research lies within the strong competition prevailing in the supply chain management and logistics environment which, new and old, is trying through various ways and incentives to consolidate their position in the logistics market.

We observed that the main processes involved in a supply chain are purchasing, warehousing, inventory management, transport and distribution network. These processes are equally important to improve the efficiency and effectiveness of supply chain and therefore should be treated in the same way with attention (Saccomano Ann, 1999)

From our study we conclude that supply chain management and logistics is by nature a tedious and complex process. The fact that it comprises a large number of procedures and that it involved many individuals, demonstrates the truth of the above finding (Parasuraman A., Zeithami V. A. and Berry L. L., 1985). 
The aim of every supply chain is to gain competitive advantage, satisfaction-customer service, increased efficiency and increased profitability. However, the most important thing for the proper functioning and the achievement of supply chain objectives is to address it as a unified set of procedures. Through the adoption of this theory, and proper coordination of the enclosing processes, it is possible to achieve the desired increase of the effectiveness and efficiency of the supply chain that will reflect into increased profitability of all those involved (stakeholders) and not just part of them (Sabath E. Robert, 1978).

The general understanding of the whole issue is the optimum satisfaction of customer demands. For many companies to survive, customer service has posed to be the best method of gaining a competitive advantage. The firm can be able to significantly improve its market share and profitability by spending more on the customer service. By systematically adjusting to this, companies can firmly improve services and reduce the total cost on logistics.

\section{REFERENCES}

Anonymous, (2000) "Majority of companies fail to recognize the value of supply chain systems to improve customer relationships". Management Services, June 1999

Anonymous, (1999) "Supply chain management isn't as good as managers think", IIE Solutions 31, No 3 10, March 1999.

Ballou H. Ronald, "Business Logistics Management", Prentice-Hall International, $3^{\text {rd }}$ Edition, 1992, p. 96- 97.

Christopher Martin, (2000) "Logistics and Supply Chain Management Strategies for Reducing Cost and Improving Service", Financial Times Management, 2nd Edition, 1998, pp. 23-40, 61-62.

Kuglin A. Fred, (1998) "Customer-centered Supply Chain Management", American Management Association (AMACOM), 1998.

Loraine Blaxter, Christina Hughes \& Malcolm Tight, 1996, "How to research"', Redwood Books, Trowbridge.

La Londe J. Bernard, Zinszer H. Paul, (1976) "Customer Service: Meaning and Measurement",(Chicago: National Council of Physical Distribution Management), 1976, p. 180.

Mike Letcher, (2000) "Focus on Customer Service Inside and Out", Public Management 82, No 1215, D 2000.

Parasuraman A., Zeithami V. A. and Berry L. L., (1985) "A conceptual model of service quality and its implications for future research", Journal of Marketing, 1985, Fall, p. 49.

Sabath E. Robert, (1978) "How Much Service Do Customers Want?", Business Horizons, April, 1978, p. 26.

Saccomano Ann, (1999) "Waiting for Efficiencies to Show", Traffic World 260, No 2 24+, 1999.

Smith Carol, (2001) "Customer Service Part I: Service Leadership", Professional

Builder (Newton, Mass.: 1993) 66, No 1 45-8, Ja 2001.

Terry Harris, (1999) "The second law of supply chain management", IIE Solutions 31, No 3, Mr 1999, WilsonWeb.

Theodore J. Stank and David J. Closs, "World Class Logistics: The Challenge of 